and fixed by gentle heat. Homologous antibody conjugated with FITC at its routinely used dilution was applied to several smears and left in a moist atmosphere at room temperature for 20 minutes. The smears were washed (with a final rinse in distilled water), dried, and mounted. Excess mountant was removed by applying pressure on the cover glass. To obtain the best optical resolution with mountant A smears must be dry and covered with the minimum amount of reagent.

Slides were examined by means of a Union inverted microscope equipped with a tungsten halogen lamp, a Tiyoda darkfield condenser with toric lens, an all-dielectric interference primary filter with a matching secondary filter (Heimer and Taylor, 1972). Measurements of immunofluorescence emission were made within an hour of mounting as well as after storage at $4^{\circ} \mathrm{C}$ and at $-20^{\circ} \mathrm{C}$. The equipment and procedure for making such measurements in terms of candelas per square metre $\left(\mathrm{cd} \mathrm{m}^{-2}\right)$ are described elsewhere (Taylor and Heimer, 1973).

\section{Results}

As can be seen from the figure, emission from preparations mounted and stored at $-20^{\circ} \mathrm{C}$ was for mountant A approximately $500 \mathrm{~cd} \mathrm{~m}^{-2}$, for mountant B $430 \mathrm{~cd} \mathrm{~m}^{-2}$, and for mountant C $350 \mathrm{~cd} \mathrm{~m}^{-2}$. All preparations stored at $4^{\circ} \mathrm{C}$ showed considerable diminution of fluorescence emission. We therefore recommend mountant $A$, and, that if preparations are to be stored, then $-20^{\circ} \mathrm{C}$ is preferable to $4^{\circ} \mathrm{C}$.

We thank Messrs Du Pont for a generous free sample of PVA.

\section{References}

Cherry, W. B. (1970). Fluorescence emission with special reference to standardization in immunofluorescence. In Standardization in Immunofluorescence, edited by Holborow, E. J. ch. 19, pp. 127-136. Blackwell, Oxford.

Heimer, G. V., and Taylor, C. E. D. (1972), Improved immunofluoresecnce obtained with a tungsten halogen lamp in a modified inverted microscope. J. clin. Path., 25, 88-93.

Hiramoto, R., Bernecky, J., Jurand, J., and Hamlin, M. (1964). The effect of hydrogen ion concentration on fluorescent labelled antibodies. J. Histochem. Cytochem., 12, 271-274.

Jongsma, A. P. M., Hijmans, W., and Ploem, J. S. (1971). Quantitive immunofluorescence: standardization and calibration in microfluorometry. Histochemie, 25, 329-343.

Nairn, R. C. (1967). Immunological tracing: fluorescent staining. In Fluorescent Protein Tracing, 3rd ed., edited by R. C. Nairn pp. 134-135. Livingstone, Edinburgh.

Pital, A., and Janowitz, S. L. (1963). Enhancement of staining intensity in the fluorescent-antibody reaction. $J$. Bact., 86, 888889.

Rodriguez, J., and Deinhardt, F. (1960). Preparation of a semipermanent mounting medium for fluorescent antibody studies. Virology, 12, 316-317.

Taylor, C. E. D., and Heimer, G. V. (1974). Measuring immunofluorescence emission in terms of standard international physical units. J. Biol. Stand., 2 No. 1, 11-20.

Taylor, C. E. D., Heimer, G. V., Lea, D. J., and Tomlinson, A. J. H. (1964). A comparison of a fluorescent antibody technique with a cultural method in the detection of infections with Shigella sonnei. J. clin. Path., 17, 225-230.

Thomason, B. M., and Cowart, G. S. (1967). Evaluation of polyvinyl alcohols as semipermanent mountants for fluorescent-antibody studies. J. Bact., 93, 768-769.

\title{
Symposium on Anticoagulant Control
}

The International Study Group for the Organization of Anticoagulant Control ${ }^{1}$ was formed at an international symposium held on the occasion of the 3rd Mediterranean Congress on Thromboembolism in June 1973. The impetus arose from the fact that at the moment there is no correlation between results of prothrombin time tests used to regulate anticoagulant drug dosage, from hospital to hospital in most parts of the world. The aim was to promote an effective international system of anticoagulant therapy by promoting

1Secretary: Dr R. Lam Po Tang, Department of Haematology, The Prince of Wales Hospital, Randwick, NSW 2031, Australia. standardized systems of laboratory control. It is believed that when this is done a meaningful comparisen and interpretation of anticoagulant therapy can be made.

The Chairman, Dr L. Poller (Great Britain), stated that the principal aim of standardization of laboratory control of anticoagulants was to make this common form of treatment safer and more effective. An international system of anticoagulant control should be based on the development of national centres for anticoagulant control in each country. He added that WHO had an interest in these developments.

The functions of national anticoagulant control centres could be: (1) to facilitate the provision of standard or reference reagents for their hospitals; (2) to adopt욜 common system of reporting prothrombin time results. This is essential in order enable a comparison of the optimum therapeutic range for oral anticoagula $P$ therapy in various cardiovascular dis eases; (3) to promote quality controb programmes. This is to ensure a correct application of the recommended pref cedures on a local hospital basis af maintenance of high standards of tecto nical proficiency.

The British system, the only officially adopted national scheme to date, migit possibly serve as a model for othe्षि countries.

Dr Jean M. Thomson (Great Britain illustrated the difficulties in anticoagula 
dosage control which arose from the variations in laboratory technique and particularly thromboplastin reagents. These had been overcome in the British system for anticoagulant control by the use of a national thromboplastin reagent, BCT (British Comparative Thromboplastin), with an agreed system of reporting prothrombin time results (British Ratio) which has been adopted.

The developments which had occurred since the introduction of the British System included the national quality control trials. The British model has already been followed in several other countries.

Dr R. Lam Po Tang (Australia) outlined the development of the Australian project begun in 1967. Their thromboplastin is calibrated with the BCT and then distributed to laboratories throughout Australia. In addition the material is sent to hospitals in New Zealand and South East Asia.

Dr B. Bradlow (South Africa) described the standardization programme they had introduced with material matched against the BCT. A clinical study had shown that the dosage regime used in South Africa was less intense therapy than the therapeutic range employed in Britain.

Dr P. H. Pinkerton (Canada) described a comparative study using commercial reagents available in Canada alongside the BCT and a home-made standardized thromboplastin. The therapeutic ranges with the BCT and the Canadian standard reagent were both 1.8 to 3.0 whereas all the commercial Quick test reagents were much less sensitive.

Dr J. A. Iriarte (Spain) reported a study of commercial reagents calibrated against the BCT. Initial results had been encouraging.

Dr T. Mandalaki (Greece) showed the good correlation between the BCT and her own local standardized preparation.

Other contributions to the discussion were made by Dr A. Anastassov (Bulgaria), Dr F. Duckert (Switzerland), and Dr A. M. Samama (France).

L. POLLER

\section{Letters to the Editor}

\section{SI Units in Pathology: the Next Stage}

As a neurologist and occasional reader of your Journal I studied with interest Professor D. N. Baron's signed leader in (J. clin. Path., 26, 729-730). Some of the innovations which he predicts for the second stage of the introduction of SI units in Britain are well known to personnel in the wards and laboratories of the University Hospital of Wales where they have been used continuously since the hospital was opened two years ago.

The changes which include using the mole (mol) as the measure of all chemical substances of known structure are generally welcome although they have sometimes produced diversity in place of uniformity. Chemical analysis, for example, of the cerebrospinal fluid (csf) reports protein in grams per litre $(\mathrm{g} / \mathrm{l})$ but glucose and chloride in millimoles per litre $(\mathrm{mmol} / \mathrm{l})$ whereas previously all three were expressed uniformly in milligrams per decilitre $(\mathrm{mg} / \mathrm{dl})$.

At the risk of seeming conservative and hypercritical of a major advance in scientific communication might I claim for the csf glucose that immunity from standardization which, according to Professor Baron, has been granted to blood haemoglobin in Britain where its concentration will continue to be expressed in grams per decilitre $(\mathrm{g} / \mathrm{dl})$ ?

Since the streptomycin revolution the level of glucose in the csf has proved a sensitive index of the chemical changes in the fluid at the onset, and during the treatment, of tuberculous meningitis. In SI units, however, the critical levels between $30 \mathrm{mg} / \mathrm{dl}$ and $50 \mathrm{mg} / \mathrm{dl}$ are compressed into the much narrower range between $1.7 \mathrm{mmol} / 1$ and $2.8 \mathrm{mmol} / 1$. The clinician has thereby lost a well tried vernier.

Might the 'working party of representatives of many relevant laboratory-based organizations' consider this and other related facets of the revolution which they so laudably contemplate?

\section{SI Units and Concentration of Glucose} in Cerebrospinal Fluid

I am grateful to Dr Wells for his interes? and for raising an important point.

The precision of csf glucose analyse under normal laboratory conditions is not better than $2 \mathrm{mg} / \mathrm{dl}$, or $0.11 \mathrm{mmol} / \mathrm{l}$ Therefore expression of csf glucose results to the nearest unit milligram, implying, fof example, that $38 \mathrm{mg} / \mathrm{dl}$ necessarily $\mathrm{re} \overrightarrow{0}$ presents a truly higher concentration than$37 \mathrm{mg} / \mathrm{dl}$, is invalid: the wise laboratory at best gives glucose results at $2 \mathrm{mg} / \mathrm{d}$. intervals. If the laboratory now gives these results at $0.1 \mathrm{mmol} / 1$ intervalsy nothing has been lost.

D. N. BARONSת

Department of Chemical Pathology Royal Free Hospital? 